\title{
What exactly are we doing to improve low lung cancer survival in the United Kingdom?
}

\author{
Eric Lim, ${ }^{1}$ Sanjay Popat ${ }^{2}$
}

\section{LOW LUNG CANCER SURVIVAL}

When one is presented with a blinded report of survival rates for lung cancer across developed countries, how can one identify the result for the UK? Exactly, choose the one with the poorest outcome. You would be correct more often than not (unless Denmark was included).

In 2007 and 2009, the EUROCARE Group published results of cancer survival identifying the UK among the countries with the lowest survival rates for lung cancer in Europe. ${ }^{12}$ As expected, this was met with a degree of outrage and attribution of poor UK results to differences in population characteristics and quality of reporting. An articulate defence launched by Moller et al hypothesised 'less favourable stage distribution in the United Kingdom' as the likely explanation for poor UK outcomes compared with other European countries compounded by suspicion of incomplete ascertainment of deaths' in certain countries reporting high survival results. ${ }^{3}$ Apart from population characteristics and quality of reporting, socioeconomic status within Europe (a surrogate for healthcare spending for the management of lung cancer) has also been cited rendering such comparisons inequitable. ${ }^{4}$

This week in Thorax, the International Cancer Benchmarking Partnership published survivorship of patients with lung cancer in six 'wealthy countries', namely, Australia, Canada, Denmark, Norway, Sweden, and of course, the UK between 1995 and 2007.5 The socioeconomic status differences have been redressed and stage adjustment rectified. At last, the UK has a chance to perform on an equal footing! So, with baited breath, you ask, 'How did we perform?'

In answer to your question, we are pretty much at the bottom-again.

If you are still waiting for further and better and higher quality evidence that the UK performs poorly, continue doing

\footnotetext{
${ }^{1}$ Department of Thoracic Surgery, The Royal Brompton Hospital, London, UK; ' 2 Department of Medicine, The Royal Marsden Hospital, London, UK

Correspondence to Eric Lim, The Royal Brompton Hospital, Sydney Street, London SW3 6NP, UK; e.lim@rbht.nhs.uk
}

nothing, but the importance of low-stage specific survival suggests that other explanations such as poorer lung cancer treatment need to be considered.

Fortunately, moves are afoot to quantify and address the quality of cancer care in the UK. Arguably the most important initiative was the launch of the National Lung Cancer Audit (NLCA) — without data, we would be lost, with no idea where we are and where we need to go. Numerous measures are reported annually by the NLCA and currently a consistent message is wide differences in the delivery of lung cancer care in the UK. Following from the initial focus on surgery, data from NLCA will be jointly reviewed with the national radiotherapy dataset and the systemic anticancer therapy dataset. It is anticipated that further regional variation in uptake and delivery of these two important modalities of lung cancer therapy will be quantified. Relatively speaking, reducing variation is likely to be the lowest hanging fruit, a focus of the UK Improving Lung Cancer Outcomes Project, a collaboration between the Royal College of Physicians, National Health Service (NHS) Information Centre, the Roy Castle Foundation, Macmillan and NHS Cancer Improvement.

\section{LOW LUNG CANCER SURGICAL RESECTION RATES}

In the first NLCA report for the audit period 2005, surgical resection for confirmed non-small cell lung cancer in the UK was documented at $10 \%$ (in contrast to other countries with better lung cancer survival), and by the period 2011, it was $14.7 \%$ in England and Wales. Updated guidelines on the radical management of lung cancer and increased national awareness may have contributed. ${ }^{6}$ NLCA data highlighted the importance of specialist thoracic surgeons and surgical attendance at multi-disciplinary team meetings as factors associated with higher lung cancer resection rates $^{7}$ and survivorship from patients operated on in high-volume specialist thoracic surgical centres will soon be available.

\section{LOW LUNG CANCER TREATMENT UTILISATION}

When undertaking comparisons of variations in international drug usage, it became evident that the UK ranked lowly in the usage of cancer drugs that were launched within the last 5 years, and in response, the English Cancer Drugs Fund was launched. ${ }^{8}$ However, there has remained considerable variation and delay in drug approval. For example, gefitinib was approved by the National Institute of Clinical Excellence (NICE) in July 2010, 1 year after European Medicines Agency (EMEA) approval. The same drug, for the same indication, was rejected by the Scottish Medicines Consortium (SMC) in May 2010, leaving Scotland without an active first-line epidermal growth factor receptor (EGFR) inhibitor until erlotinib was approved in January 2012.

\section{(S)LOW UPTAKE OF ADVANCES}

IN LUNG CANCER MANAGEMENT

One difficult question to address is the continuous and increasing cost of healthcare delivery. The financial pressures for the NHS today cannot be compared to when it was founded in 1948. As we develop as a medical profession, we are now increasingly aware of the importance to return to patient-centred care. 9 One important aspect is joint clinician and patient decision-making that leads to greater satisfaction and better outcomes in healthcare delivery. ${ }^{10}$ However, as a statefunded service, the NHS cannot be disassociated from health economics and neither can it be expected to be, as money is finite. Difficult decisions must be made to balance the cost of healthcare against benchmark values, but this can conflict with patient choice as differences in what would constitute 'value' to a patient or clinician may not be consistent with that applied to a country, especially when the 'cost' aspect is not 'visible' or appreciated. Take lung cancer screening as an example: after the results of the American National Lung Cancer Screening Trial was published in 2011, ${ }^{11}$ expert bodies from the American Society of Clinical Oncologists, the American College of Chest Physicians, ${ }^{12}$ and separately, the American Association for Thoracic Surgeons ${ }^{13}$ all recommend lung cancer screening to reduce 5 -year lung cancer-related death by $20 \%$. Where are we in the UK on this?

\section{LOW LUNG CANCER RESEARCH FUNDING}

The National Cancer Research Institute identified the poor positioning of lung cancer research in the UK as longstanding in a reported published in $2006^{14}$ and made a number of recommendations aimed at increasing lung cancer research. Research brainstorming among the lung cancer 
multidisciplinary teams happens at the Annual British Thoracic Oncology Group Meeting, where protocols are developed and designed by the foremost experts in the UK on the management of lung cancer and presented in dedicated sessions to the support of attendees who represent the lung cancer multidisciplinary team across the UK. Despite persistent calls to encourage research in lung cancer, and particularly, in surgery, ${ }^{15}$ it remains to be answered why a divide exists in proposals that were considered important to the lung cancer community (such as a comparison of surgery against stereotactic body radiotherapy and surgery for small cell lung cancer) but not the grant funding bodies.

\section{BUT NO LACK OF WILLINGNESS OR MOTIVATION}

Lung cancer resection rates are increasing in the UK, and data on variation in treatment continue to be collated. Cancer Research UK recently recognised the unmet need for lung cancer research, the huge potential clinical impact, and met this with dedicated research funding. Meanwhile, phase 1 of their Stratified Medicine Programme has been a resounding success for participating lung cancer patients and clinicians, allowing molecularly stratified patients to then potentially receive genotype-directed targeted therapy in innovative clinical trials. New dedicated lung cancer research funding streams have emerged from charities such as the Roy Castle Foundation.

Some measures (reducing variation) are likely to have an impact in the short term, while others (policy changes, introduction of new treatments, changes in management and research) will take much longer. When compounded with the time lag in registry reporting, substantial amount of time is likely to be required before any favourable impact on survival becomes evident in future publications.

Contributors EL and SP contributed to writing the editorial.

\section{Competing interests None.}

Provenance and peer review Commissioned; internally peer reviewed.

To cite Lim E, Popat S. Thorax 2013;68:504-505.

Published Online First 10 April 2013

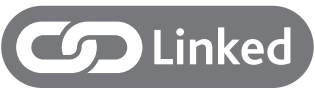

http://dx.doi.org/10.1136/thoraxjnl-2012-202297

Thorax 2013:68:504-505.

doi:10.1136/thoraxjnl-2013-203543

\section{REFERENCES}

1 Verdecchia A, Francisci S, Brenner $\mathrm{H}$, et al. Recent cancer survival in Europe: a 2000-02 period analysis of EUROCARE-4 data. Lancet Oncol 2007;8: 784-96.

2 Sant M, Allemani C, Santaquilani M, et al. EUROCARE-4. Survival of cancer patients diagnosed in 1995-1999. Results and commentary. Eur J Cancer 2009:45:931-91.

3 Moller $\mathrm{H}$, Linklater KM, Robinson D. A visual summary of the EUROCARE-4 results: a UK perspective. Br J Cancer 2009;101(Suppl 2): S110-14.

4 Erridge SC, Moller $\mathrm{H}$, Price A, et al. International comparisons of survival from lung cancer: pitfalls and warnings. Nat Clin Pract Oncol 2007;4: 570-7.
5 Walters S, Maringe C, Coleman MP, et al. Lung cancer survival and stage at diagnosis in Australia, Canada, Denmark, Norway, Sweden and the UK: a population-based study, 2004-2007. Thorax 2013:68:551-64.

6 Lim E, Baldwin D, Beckles M, et al. Guidelines on the radical management of patients with lung cancer. Thorax 2010;65(Suppl 3):iii1-27.

7 Lau KK, Rathinam S, Waller DA, et al. The effects of increased provision of thoracic surgical specialists on the variation in lung cancer resection rate in England. J Thorac Oncol 2013;8:68-72.

8 Extent and causes of international variations in drug usage. 2010. http://www.dh.gov.uk/en/ Publicationsandstatistics/Publications/ PublicationsPolicyAndGuidance/DH_117962 (accessed 10 Mar 2013).

9 Gabriel SE, Normand SL. Getting the methods rightthe foundation of patient-centered outcomes research. N Engl J Med 2012;367:787-90.

10 Joosten EA, DeFuentes-Merillas L, de Weert GH, et al. Systematic review of the effects of shared decision-making on patient satisfaction, treatment adherence and health status. Psychother Psychosom 2008;77:219-26.

11 The National Lung Screening Trial Research Team. Reduced lung-cancer mortality with low-dose computed tomographic screening. New Eng J Med 2011;365:395-409.

12 Bach PB, Mirkin JN, Oliver TK, et al. Benefits and harms of CT screening for lung cancer: a systematic review. JAMA 2012:307:2418-29.

13 Jaklitsch MT, Jacobson FL, Austin JH, et al. The American Association for Thoracic Surgery guidelines for lung cancer screening using low-dose computed tomography scans for lung cancer survivors and other high-risk groups. J Thorac Cardiovasc Surg 2012;144:33-8.

14 Lung Cancer Research in the UK. National Cancer Research Institute, 2006. http://www.ncri.org.uk/ includes/Publications/reports/LCReport.pdf (accessed 10 Mar 2013).

15 Challenges and opportunities in surgical cancer research in the UK. National Cancer Research Institute, 2012. http://www.ncri.org.uk/includes/ Publications/reports/ncri_surgical_research_report__final.pdf (accessed 23 Mar 2013). 